Case Report

\title{
Bilateral Iris Atrophy after the Femtosecond Assisted Laser In Situ Keratomileusis Surgery
}

\author{
Kenan Olcay, ${ }^{1}$ Akin Cakir, ${ }^{2}$ Sercan Koray Sagdic, ${ }^{3}$ Eyup Duzgun, ${ }^{3}$ and Yildiray Yildirim ${ }^{3}$ \\ ${ }^{1}$ Department of Ophthalmology, Gumussuyu Military Hospital, 34100 Besiktas, Istanbul, Turkey \\ ${ }^{2}$ Department of Ophthalmology, Golcuk Military Hospital, 41650 Golcuk, Kocaeli, Turkey \\ ${ }^{3}$ Department of Ophthalmology, Gulhane Military Medical Academy Haydarpasa Training Hospital, 34668 Uskudar, Istanbul, Turkey
}

Correspondence should be addressed to Yildiray Yildirim; doctoryyildirim@gmail.com

Received 23 April 2015; Accepted 4 June 2015

Academic Editor: Giacomo Savini

Copyright (C) 2015 Kenan Olcay et al. This is an open access article distributed under the Creative Commons Attribution License, which permits unrestricted use, distribution, and reproduction in any medium, provided the original work is properly cited.

\begin{abstract}
Purpose. To report an unknown complication of laser in situ keratomileusis (LASIK) surgery. Case Presentation. A 28-year-old female presented with photophobia and glare to our eye service. She stated in her medical history that she had undergone femtosecond assisted LASIK surgery in both eyes 15 months ago and her symptoms started just after this surgery. On admission, her best-corrected visual acuity was 10/10 in both eyes. She had mydriatic pupils with no direct light reflex. Examination of the anterior segment revealed bilateral iris atrophy projecting within the LASIK ablation zone and a transillumination defect was remarkable on the slit lamp examination. Conclusion. We hypothesized that this condition may have been caused by the abnormally increased IOP that resulted in ischemia in the iris vascular plexus during the suction process of surgery.
\end{abstract}

\section{Introduction}

Refractive surgery has undergone significant progress and evolution during the past two decades with the advent of the excimer laser. Excimer laser refractive surgical options mainly include photorefractive keratectomy (PRK) and laser in situ keratomileusis (LASIK) [1]. Since FDA approval in 2000 , the femtosecond laser has revolutionized the creation of flaps for LASIK and is being used confidently at the present time. Herein we report an interesting and previously unreported complication of this procedure.

\section{Case Presentation}

A 28-year-old female presented with photophobia and glare to our eye service. She stated in her medical history that she had undergone femtosecond assisted LASIK surgery in both eyes 15 months ago and her symptoms started just after this surgery. Preoperative medical records of the patient revealed $-4.75(-1.00 \times 175)$ in the right eye and $-4.50(-0.50 \times 180)$ in the left eye and otherwise a normal ophthalmological examination. On admission, her best-corrected visual acuity was 10/10 in both eyes. She had mydriatic pupils with no direct light reflex. Visual fields were full to confrontation in both eyes. Examination of the anterior segment revealed bilateral iris atrophy projecting within the LASIK ablation zone (Figure 1) and a transillumination defect was remarkable on the slit lamp examination (Figure 2). Funduscopy and intraocular pressures (IOP) were normal in both eyes.

\section{Discussion}

Several flap-related or intraoperative complications of femtosecond assisted LASIK surgery are reported in the literature [1]. However, there is no case presented with such a clinical situation, to the best of our knowledge. Many studies have investigated the effects of LASIK surgery on intraocular pressure and ocular blood flow [2-6]. In a study ocular blood flow changes following LASIK were evaluated using color Doppler imaging and a highly significant decrease in the peak systolic volume and end-diastolic volume of the ophthalmic artery at 1 day and 1 week postoperatively was reported [2]. Yang et al. evaluated the effect of intraocular pressure on blood flow velocity and resistance in the rabbit ophthalmic artery, 


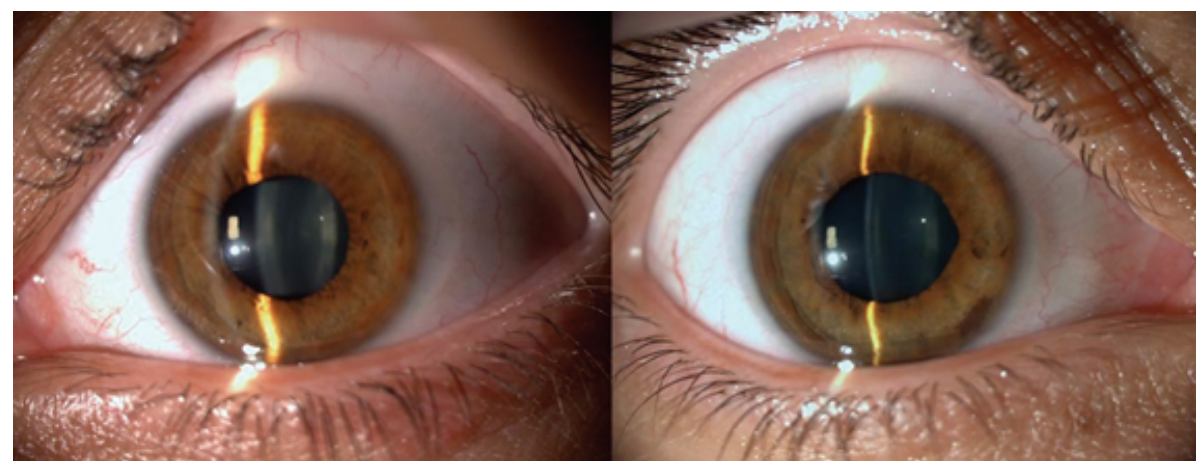

FIGURE 1: Bilateral iris atrophy correlated with the ablation zone and middilated pupils (due to the probable ischemic damage of the iris sphincter muscle).

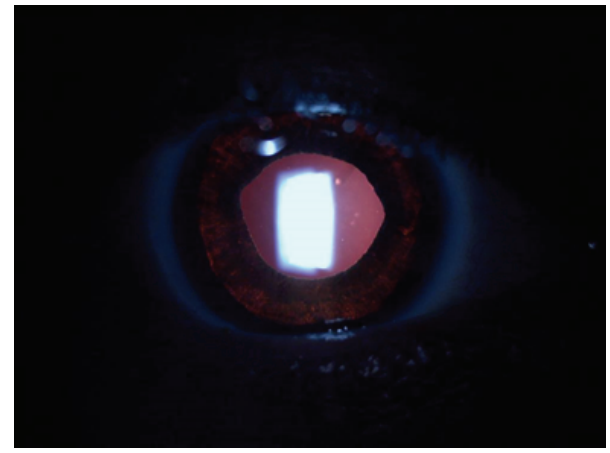

FIGURE 2: A transillumination defect is remarkable on the biomicroscopic examination.

reporting that the ophthalmic artery in rabbits was capable of maintaining normal blood velocity and resistance when IOP was below $40 \mathrm{mmHg}$. However, the autoregulatory capacity was greatly limited when IOP was over $40 \mathrm{mmHg}$ [7]. Vetter et al. compared the increase in intraocular pressure (IOP) during corneal flap preparation in porcine eyes when using a femtosecond laser or a mechanical microkeratome and reported that during the worst-case procedure (the eye interface was lowered against the globe until abortion of the docking maneuver when using the IntraLase femtosecond laser or the suction ring was pressed very firmly against the globe when using the Amadeus microkeratome), a maximum IOP of $260 \pm 53 \mathrm{mmHg}$ was reached with the IntraLase and $318 \pm$ $59 \mathrm{mmHg}$ was reached with the Amadeus microkeratome [3]. Vetter et al. also reported that the IOP may be elevated to the range of 299.1 to $341.2 \mathrm{mmHg}$ during the worst-case procedure (femtosecond laser interface was pressed against globe until docking maneuver was aborted) with the $60 \mathrm{kHz}$ femtosecond lasers in human donor eyes [8]. In another study, real-time intraocular pressure was compared between laser in situ keratomileusis (LASIK) and epithelial LASIK (epiLASIK) in porcine eyes during flap creation using a microkeratome or an epikeratome, respectively. In the LASIK group, the mean IOP was $113.65 \pm 10.78$ during suctioning and $112.35 \pm 11.51 \mathrm{mmHg}$ during cutting phases and in the epiLASIK group, the mean IOP was $92.57 \pm 20.86 \mathrm{mmHg}$ during suctioning, $82.09 \pm 20 \mathrm{mmHg}$ during cutting phases [4].
All these studies show the significant effects of LASIK surgery on intraocular pressure and ocular hemodynamics. In the literature optic neuropathy cases have been reported following LASIK surgery and it has been considered that this complication might be a result of barotrauma or ischemia related to extremely elevated intraocular pressure during a portion of the LASIK procedure [9-11]. Therefore, we hypothesized that bilateral iris atrophy may have been caused by the abnormally increased IOP that resulted in ischemia in the iris vascular plexus during the suction process in our case.

\section{Disclosure}

The paper was presented at 19th European Society of Cataract and Refractive Surgeons Winter Meeting on Feb 20-22, 2015, Istanbul, Turkey. The paper has not been previously published.

\section{Conflict of Interests}

The authors declare that there is no conflict of interests regarding the publication of this paper.

\section{References}

[1] S. C.-M. Huang and H.-C. J. Chen, "Overview of laser refractive surgery," Chang Gung Medical Journal, vol. 31, no. 3, pp. 237-252, 2008.

[2] W. Abou Samra, M. Shahin, H. El-Awady, A. A. El-Rahman, and N. El-Toukhy, "Assessment of ocular hemodynamics after laser in situ keratomileusis using color Doppler imaging," International Ophthalmology, vol. 34, no. 2, pp. 269-275, 2014.

[3] J. M. Vetter, A. Schirra, D. Garcia-Bardon, K. Lorenz, W. E. Weingärtner, and W. Sekundo, "Comparison of intraocular pressure during corneal flap preparation between a femtosecond laser and a mechanical microkeratome in porcine eyes," Cornea, vol. 30, no. 10, pp. 1150-1154, 2011.

[4] J. L. Hernández-Verdejo, L. de Benito-Llopis, and M. A. Teus, "Comparison of real-time intraocular pressure during laser in situ keratomileusis and epithelial laser in situ keratomileusis in porcine eyes," Journal of Cataract and Refractive Surgery, vol. 36, no. 3, pp. 477-482, 2010. 
[5] J. M. Vetter, M. Faust, A. Gericke, N. Pfeiffer, W. E. Weingärtner, and W. Sekundo, "Intraocular pressure measurements during flap preparation using 2 femtosecond lasers and 1 microkeratome in human donor eyes," Journal of cataract and refractive surgery, vol. 38, no. 11, pp. 2011-2018, 2012.

[6] C. Strohmaier, C. Runge, O. Seyeddain et al., "Profiles of intraocular pressure in human donor eyes during femtosecond laser procedures," Investigative Ophthalmology and Visual Science, vol. 54, no. 1, pp. 522-528, 2013.

[7] Q. Yang, J. Shen, W. Guo, J. Wen, Z. Wang, and D. Yu, "Effect of acute intraocular pressure elevation on blood flow velocity and resistance in the rabbit ophthalmic artery," Veterinary Ophthalmology, vol. 14, no. 6, pp. 353-357, 2011.

[8] J. M. Vetter, M. Faust, A. Gericke, N. Pfeiffer, W. E. Weingärtner, and W. Sekundo, "Intraocular pressure measurements during flap preparation using 2 femtosecond lasers and 1 microkeratome in human donor eyes," Journal of Cataract and Refractive Surgery, vol. 38, no. 11, pp. 2011-2018, 2012.

[9] A. G. Lee, T. Kohnen, R. Ebner et al., "Optic neuropathy associated with laser in situ keratomileusis," Journal of Cataract and Refractive Surgery, vol. 26, no. 11, pp. 1581-1584, 2000.

[10] B. D. Cameron, N. A. Saffra, and M. B. Strominger, "Laser in situ keratomileusis-induced optic neuropathy," Ophthalmology, vol. 108, no. 4, pp. 660-665, 2001.

[11] S. R. Montezuma, S. Lesseil, and R. Pineda, "Optic neuropathy after epi-LASIK," Journal of Refractive Surgery, vol. 24, no. 2, pp. 204-208, 2008. 


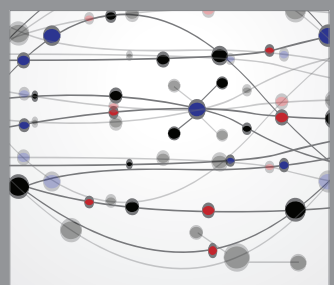

The Scientific World Journal
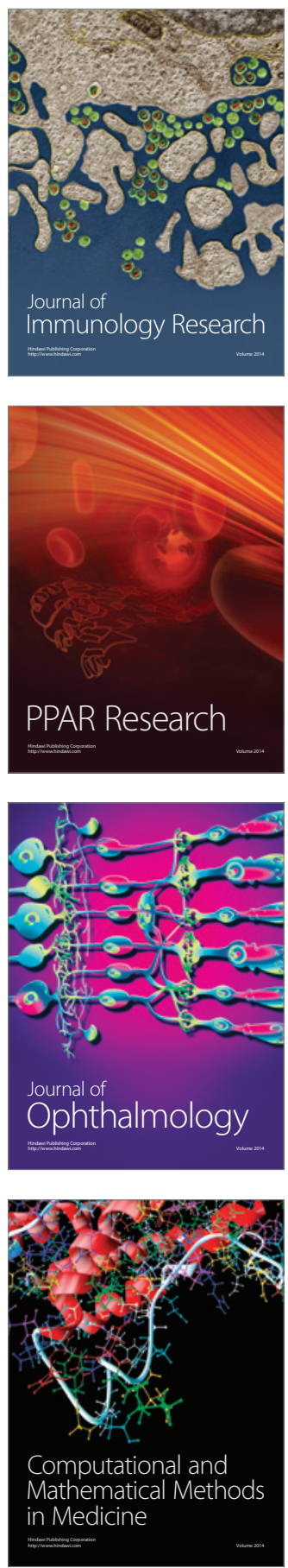

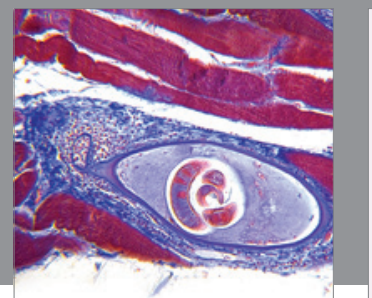

Gastroenterology

Research and Practice
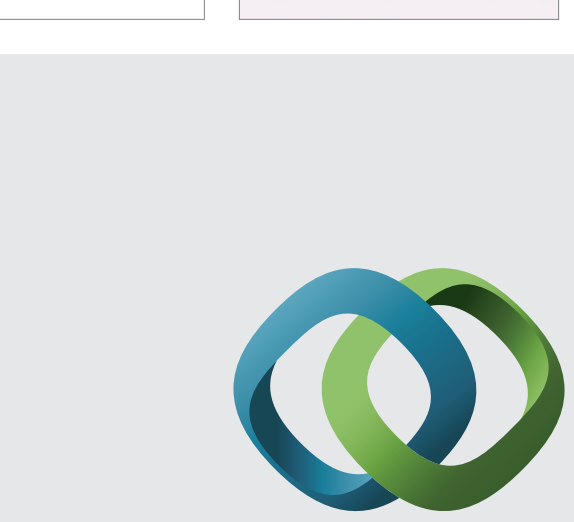

\section{Hindawi}

Submit your manuscripts at

http://www.hindawi.com
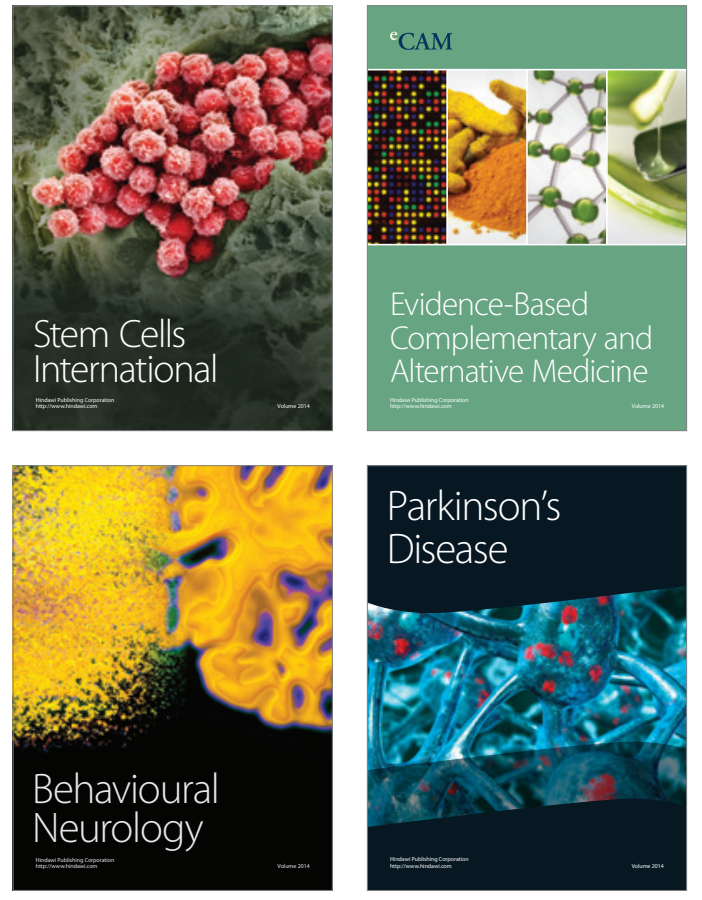
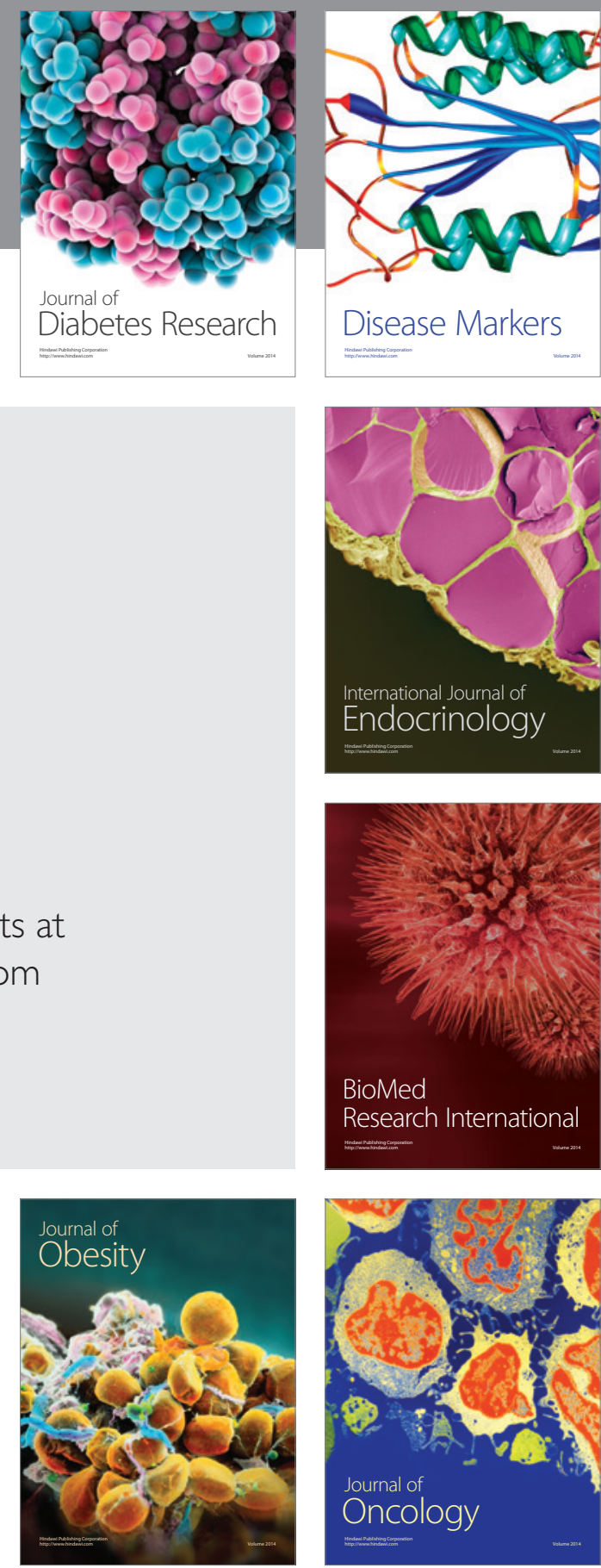

Disease Markers
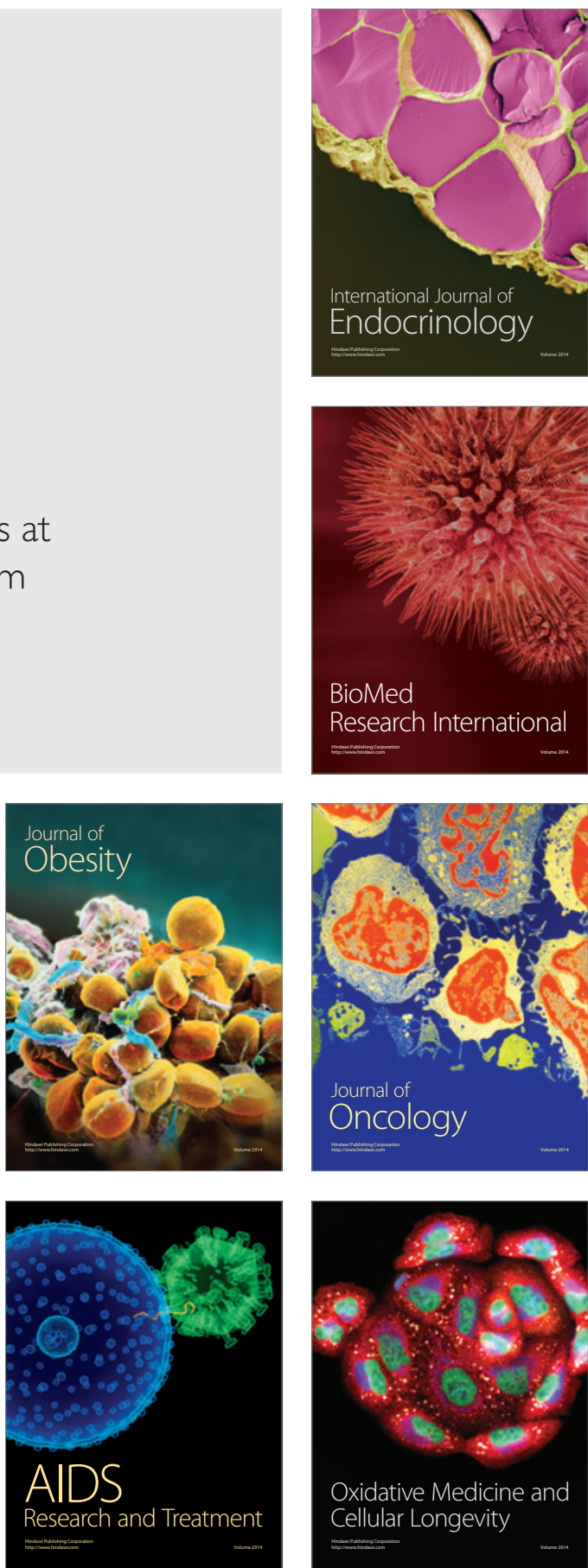